\title{
Injury and Injury Prevention in United States Para Swimming: A Mixed-Methods Approach
}

Jay Salerno, PT, DPT ${ }^{1}$, Stephanie Tow, MD² Elizabeth Regan, DPT, PhD ${ }^{3}$, Stephen Bendziewicz, $\mathrm{PT}$, DPT ${ }^{4}, \mathrm{Matthew}$ McMillan, PT, DPT ${ }^{5}$, Shana Harrington, PT, $\mathrm{PhD}^{3}{ }^{\mathrm{a}}{ }^{\mathrm{a}}$

1 Prisma Health Apex Athletic Performance, Lexington, SC, USA, ${ }^{2}$ Department of Physical Medicine \& Rehabilitation, University of Texas Southwestern Medical Center, ${ }^{3}$ Department of Exercise Science, Physical Therapy Program, University of South Carolina, Columbia, SC, USA, 4 Jumpstart Pediatrics, Chapin, SC, USA, 5 Interim Healthcare of the Upstate, Greenville, SC, USA

Keywords: para swimming, swimming, injury, injury prevention

https://doi.org/10.26603/001c.31173

\section{International Journal of Sports Physical Therapy}

Vol. 17, Issue 2, 2022

\section{Background}

Para swimming has experienced increased participation in recent years. Injury and injury prevention research on Para swimmers is lacking compared to swimmers without impairment.

\section{Purpose}

This study aimed to gather data in Para swimmers on typical injuries, injury prevention programs, and attitudes toward injury and injury prevention in this population.

\section{Study Design}

Cross-sectional, mixed-methods design evaluating injuries, injury management, and injury prevention in elite Para swimmers in United States (U.S.).

\section{Methods}

Para swimmers on the U.S. Paralympics Swimming National teams at multiple competition levels were invited to complete an online survey. Qualitative interviews with six U.S. Paralympics National team Para swimmers were conducted to provide detail on athlete experiences with injury and prevention.

\section{Results}

Twenty-one of 56 surveys were returned: 11 of 21 participants (52.4\%) reported experiencing an injury that altered their weekly training. All (21/21) reported participating in strength training and 19 of 21 (90.5\%) reported incorporating stretching into their training regimen, although strengthening/stretching regimens included routines that may not have been specifically targeted toward injury prevention. Six of 21 (28.6\%) reported participation in an injury prevention program. Qualitative interview themes included the impact of swimmers' compensated body mechanics on injury risk, the value of individualized injury prevention programs, and the importance of knowledgeable coaching and rehabilitation staff.

\section{Conclusions}

Injury prevention programs are important components in Para swimming training although they are underutilized based on responses in this study. These programs should be individualized to address swimming biomechanics and athlete-specific impairments. Increasing coaching knowledge and access to individualized programs may reduce injury prevalence among this at-risk population. 


\section{Level of Evidence}

3

\section{INTRODUCTION}

The Paralympic movement has gained significant momentum over the past century. The Paralympic Games includes athletes with various physical, visual, and intellectual impairments and have evolved into an elite level of competition. ${ }^{1,2}$ The International Paralympic Committee oversees the Paralympics, which has traditionally focused on elite sports performance or helping individuals with disabilities train in sports to become future elite athletes.

Classification systems were developed and have evolved for each sport intending to make the competition as fair as possible. The goal of classification is to group Para athletes who have a similar degree of sport-specific activity limitation from their impairment into a sport class. ${ }^{3}$ World Para Swimming governs Paralympic Swimming classification, and the classification process results in three separate sport classes per athlete evaluation: a $S$ class for freestyle, backstroke, and butterfly, a SB class for breaststroke, and a SM class for individual medley. For physical impairments, sport classes range from S1 through S10 / SB1 through SB9 / SM1 through SM10, with the lower numbers representing more severe physical impairment/limitation in swimming. ${ }^{4}$ The visual impairment sport classes range from S11/SB11/ SM11 through S13/SB13/SM13, with the lower numbers representing more severe vision impairment. ${ }^{4}$ Within each sport class, Para swimmers may also have variability in their swimming performance, reflective of their training, experience, and inherent athleticism and not impacted by their impairment, similar to how swimmers without disabilities may have varying swimming performance within an age group. One may assume that certain sport classes experience greater functional limitations when injured due to their physical impairments, but this relationship remains unclear. $^{5}$

As the Paralympic movement gains increasing commercial support and media coverage, more generations of individuals with disabilities are inspired to participate in sports. With the growing population of Para athletes, there is an increased need to understand injury epidemiology and injury prevention strategies for Para athletes. A qualitative study conducted by Fagher and colleagues interviewed 18 Swedish Para athletes representing 10 different Para sports and revealed that Para athletes' views of their sports-related injuries experiences are complex, multifactorial, and distinct from the perspectives of athletes without disabilities in terms of injury causes, risk behavior, impacts on function after injury, psychosocial stressors, and overall consequences of injury. ${ }^{6}$ For instance, one Para athlete noted, "I'm often thinking, what will happen if I get an injury to my non-disabled side, I wouldn't be able to manage my daily life. That's what I'm afraid of."6

Currently, most published Para sports injury epidemiology data have been from the Paralympic Games. ${ }^{5,7-11}$ Studies from the Rio 2016 and London 2012 Summer Paralympic Games reported $8.5 \%$ - $12.4 \%$ of Para swimmers had a current injury ${ }^{12}$ with the highest percentage of injuries being acute (47\%), followed by overuse (37\%), and then acute on chronic (16\%). ${ }^{12}$ Past studies have reported higher injury rates in Para swimmers, Reynolds and colleagues found 69\% of Para swimmers on the British team reporting injuries during the Barcelona 1992 Summer Paralympic Games. ${ }^{13}$ Outside of the elite competition, there is a lack of published studies that include Para swimmers and their injury patterns. To our knowledge, there have been no recent studies describing Para swimmers' injury patterns outside of the Paralympic Games.

Due to the lack of published research on injuries and injury prevention specific to Para swimming outside of the Paralympic Games, Para swimmers often rely on current knowledge and evidence for injury prevention in swimmers without disabilities. Many injuries to swimmers without impairment are at the shoulder and are commonly a result of overuse. ${ }^{14}$ Risk factors for shoulder injuries in swimmers include high training volumes, muscle fatigue/overload (especially of the subscapularis and serratus anterior), rotator cuff tendinosis, shoulder laxity, and impingement positions during swim stroke. ${ }^{15}$ Injury prevention programs for swimmers should include strengthening, stretching, and endurance training. It should also include stroke-specific instruction on body mechanics such as decreasing internal rotation of the shoulder during recovery, breathing bilaterally, or shortening stroke follow-through. ${ }^{15,16}$ However, Para swimmers may have different risk factors for injuries compared to swimmers without disabilities due to Para swimmers' underlying impairments. For instance, depending on the Para swimmer's underlying medical condition(s) and impairment(s), they may have anatomical or functional differences that alter swimming biomechanics, compensatory biomechanics, and techniques to accommodate their impairments but also increase the risk of an overuse injury.

To better understand injuries, injury risk, and prevention in Para swimmers at all competition levels studies are needed outside of the Paralympic Games. Therefore, the purpose of this study was to investigate U.S. Para swimmers with physical or visual impairments at various competition levels and (1) describe injuries related to Para swimming, (2) understand athletes' participation in injury prevention programs and the characteristics of those programs, and (3) evaluate athletes' perceptions of injury risk, complications, and treatment.

\section{METHODS}

Design: A cross-sectional, mixed-methods approach evaluating injuries, injury management, and injury prevention related to Para swimming in U.S. National team Para swimmers was used for this study. The first part of the study consisted of a one-time online survey. A previous survey developed for Para athletes was used to help guide the development of the survey used in this study. ${ }^{17}$ Additionally, input from the U.S. Chief of Paralympic Sport and the U.S. Paralympics Swimming High-Performance Director was sought and the initial survey was piloted for any feedback 
and edits. An online survey (REDCap ${ }^{\circledR}$ version 7.6.0, Vanderbilt University, Nashville, TN) was utilized, hosted and distributed through University of South Carolina, (Appen$\operatorname{dix} 1)$.

The second part of the study consisted of qualitative semi-structured interviews via an audiovisual communication platform $\left(\right.$ Skype $\left.^{\mathrm{TM}}\right)$. The interview questions were developed by the student investigators (JS, MM, SB) as a result of the survey responses and through collaboration with a board-certified Physical Medicine \& Rehabilitation and Sports Medicine physician (ST) with a specialization in Para Sports Medicine. The focus of the interviews was to gather comprehensive information on Para swimmers' perceptions and experiences with injuries, injury prevention, treatment, and the injury recovery process. The interview guide can be viewed in Appendix 2.

\section{PARTICIPANTS:}

Survey: Participants were recruited through emails distributed by the U.S. Paralympics Swimming High-Performance Director. Inclusion criteria consisted of: being able to complete the survey in English and being a member of the U.S. Paralympic Swimming National teams with either a physical or visual impairment. Participants were excluded if they were an athlete with an intellectual impairment given concern that they would not be able to appropriately complete the survey. Fifty-six participants were identified by the High-Performance Director for recruitment, the goal was to have a sample size of at least 17 responses (response rate $30.4 \%$ ) since on average, online surveys yield a response rate between $20-30 \% .{ }^{18,19}$

Qualitative Interviews: Participants were selected through a convenience sample of U.S. Para swimmers on the U.S. Paralympics Swimming National teams. Researchers requested the U.S. Paralympics Swimming High-Performance Director provided purposeful sampling of Para swimmers representing diversity in regards to primary stroke, medical diagnoses, and impairments. Inclusion criteria were: current U.S. Para swimming National team members with either a physical or visual impairment under the direction of the director. Upon the director's review of the team roster and discussions with the athletes, six Para swimmers were selected based on the request in representing a diversity of Para swimmers, schedule availability, and willingness to participate in an interview. They were encouraged to also take the survey portion of the study but were not excluded if they did not complete the survey.

This study was reviewed and approved by the University of South Carolina Institutional Review Board (Pro00081813 and Pro00084553).

\section{PROCEDURES}

Survey: Fifty-six participants on the U.S. Paralympic Swimming National teams were emailed the online survey. Email reminders were distributed after two weeks to remind participants of the study, and each week following for seven weeks, after which the survey was closed. The general definition used for injury history reporting in this study was "any injury related to swimming that altered weekly training or caused a Para swimmer to miss a competition, regardless of whether participants sought medical treatment for the injury."

Training: Student investigators were trained in qualitative interview techniques by author (ER), who is an experienced qualitative researcher, including open ended questions, follow up techniques and avoidance of leading questions. Student investigators practiced and were given feedback.

Interviews: After the survey was closed, each of the three student investigators contacted two of the six Para swimmers by email to arrange a one-on-one interview over an audiovisual communication platform $\left(\right.$ Skype $\left.^{\mathrm{TM}}\right)$. Audiovisual interviews instead of audio-only were selected as this allowed for a more personal interview. The interviewers provided the Para swimmers with an explanation of the study and potential interview questions before conducting the interview. The interviews were conversational and semi-structured to allow for in-depth follow-up. Interviews lasted between 14 and 38 minutes.

\section{DATA ANALYSIS:}

Survey Analysis: Statistical analysis was performed using a statistical software platform $\left(\right.$ IBM $^{\circledR}{ }^{\circledR}$ SPSS ${ }^{\circledR}$ Statistics for Windows, Version 26.0, Armonk, NY: IBM Corp). Descriptive statistics including means, minimum, maximum, standard deviations, and frequencies were calculated for the dependent variables.

Qualitative Analysis: Each interview was transcribed verbatim. De-identified transcripts from the interviews were input into qualitative data analysis software (QSR International Pty Ltd. (2019) NVivo, Version 12.3.0). Iterative thematic analysis ${ }^{20}$ was completed in a collaborative process by the three student investigators (JS, MM, SB) with support and review by author (ER) with qualitative research expertise. The first interview was coded by each of the three student investigators individually, then discussed as a group with author (ER) to ensure consistency between researchers in the coding process. Initial codes were completed inductively, remaining as close as possible to the participant's wording. Further iterations of the coding were completed as a group, with themes categorized both deductively into predetermined categories (demographics, injury, training, treatment) and inductively through emergent identified new themes through group consensus.

Further thematic breakdown under resultant categories were reviewed and revised in several rounds by all three student researchers (JS, MM, SB) and author (ER), and the results were reviewed with authors (SH, ST). Trustworthiness was established through comparison to survey results (triangulation) and utilizing a mentor with qualitative expertise. $^{21}$

\section{RESULTS}

\section{PART I: SURVEY RESULTS}

A total of 24 complete survey responses were received from the 56 surveys distributed to swimmers on the U.S. Paralympic Swimming National Teams (42.9\% response rate). There were no incomplete survey responses. Three of the 
Table 1. Survey Participant Demographics.

\begin{tabular}{|c|c|c|c|}
\hline & & & Number of survey participants $(n=21)$ \\
\hline \multirow{2}{*}{\multicolumn{2}{|c|}{ Gender }} & Female & $6(21.6 \%)$ \\
\hline & & Male & $15(71.4 \%)$ \\
\hline \multirow{3}{*}{ Age } & & $\begin{array}{l}14-18 \text { years } \\
\text { old }\end{array}$ & $11(52.4 \%)$ \\
\hline & & $\begin{array}{l}19-25 \text { years } \\
\text { old }\end{array}$ & $6(28.6 \%)$ \\
\hline & & $\begin{array}{l}26-30 \text { years } \\
\text { old }\end{array}$ & $4(19 \%)$ \\
\hline \multirow{3}{*}{\multicolumn{2}{|c|}{$\begin{array}{l}\text { Number of years } \\
\text { swimming } \\
\text { competitively }\end{array}$}} & $<5$ years & $3(14.3 \%)$ \\
\hline & & $5-10$ years & $11(52.4 \%)$ \\
\hline & & $>10$ years & $7(33.3 \%)$ \\
\hline \multirow{2}{*}{\multicolumn{2}{|c|}{$\begin{array}{l}\text { Highest level of } \\
\text { competition in Para } \\
\text { swimming }\end{array}$}} & International & $19(90.5 \%)$ \\
\hline & & National & $2(9.5 \%)$ \\
\hline \multirow{7}{*}{ Impairment Type } & \multirow{6}{*}{$\begin{array}{l}\text { Physical } \\
\text { impairment* }\end{array}$} & $\begin{array}{l}\text { Physical } \\
\text { impairment } \\
\text { types }\end{array}$ & $18(85.7 \%)$ \\
\hline & & Hypertonia & 2 (9.5\%) (dystonic tetraplegia, multiple traumatic brain injuries) \\
\hline & & $\begin{array}{l}\text { Impaired } \\
\text { muscle } \\
\text { power }\end{array}$ & $\begin{array}{l}3 \text { (14.3\%) (arthrogryposis amyoplasia, transverse myelitis, } \\
\text { lumbar level incomplete spinal cord injury) }\end{array}$ \\
\hline & & $\begin{array}{l}\text { Impaired } \\
\text { passive range } \\
\text { of motion }\end{array}$ & 2 (9.5\%) (arthrogryposis amyoplasia, Nager syndrome) \\
\hline & & $\begin{array}{l}\text { Limb } \\
\text { deficiency }\end{array}$ & $\begin{array}{l}9 \text { (42.9\%) (lower extremity amputations including proximal } \\
\text { femoral focal deficiency, upper extremity amputations, Nager } \\
\text { syndrome) }\end{array}$ \\
\hline & & Short stature & $\begin{array}{l}5 \text { ( } 23.8 \%) \text { (dwarfism including achondroplasia, osteogenesis } \\
\text { imperfecta) }\end{array}$ \\
\hline & \multicolumn{2}{|c|}{ Visual impairment } & $3(14.3 \%)$ \\
\hline
\end{tabular}

24 survey responses (12.5\%) were from swimmers with intellectual impairments and were excluded. Figure 1 demonstrates the recruitment process of participants.

\section{PARTICIPANT INFORMATION}

The mean age of survey participants was 19.4 years (range 14-30). Participants reported swimming competitively for a mean of 8.4 years (range 2-17). Demographics of survey participants are presented in Table 1. Only three (14.3\%) swimmers reported competing in additional sports other than swimming (shot put, Para triathlon, and archery). The most common primary swimming stroke reported was freestyle (57.1\%).

\section{IN AND OUT OF POOL TRAINING INFORMATION}

Participants reported swimming an average of 15.62 (SD 3.57) hours per week. All reported performing cross-training, with an average of 4.10 (SD 2.32) hours per week. When combining total hours of cross-training and swimming, participants averaged a total of 19.71 (SD 4.33) hours of total training per week. All of the survey participants reported

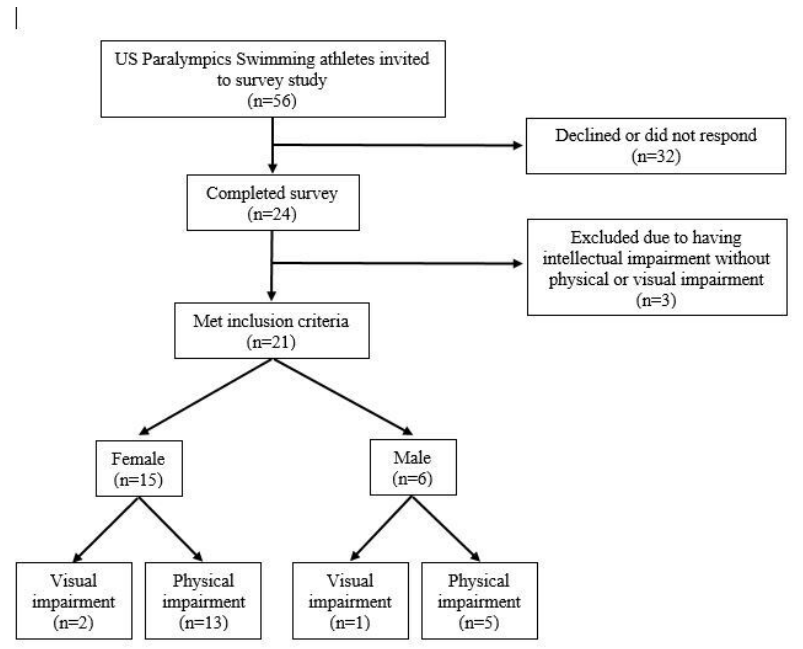

Figure 1.

using some type of resistance training outside of the pool (Table 2). 
Table 2. Reported Strength Training Out of the Pool

\begin{tabular}{|l|l|}
\hline Type* $^{*}$ & Number of Participants (\%) \\
\hline Bodyweight exercise & $20(95 \%)$ \\
\hline Dumbbells or free weights & $18(86 \%)$ \\
\hline Medicine Balls & $16(76 \%)$ \\
\hline Elastic bands & $15(71 \%)$ \\
\hline Weight machines & $10(48 \%)$ \\
\hline
\end{tabular}

*Participants could select all that apply

Table 3. Reported Resistance Training In the Pool

\begin{tabular}{|l|l|}
\hline Type $^{*}$ & Number of Participants (\%) \\
\hline Paddles & $18(86 \%)$ \\
\hline Parachutes & $17(81 \%)$ \\
\hline Fins & $16(76 \%)$ \\
\hline Bungee cords & $12(57 \%)$ \\
\hline Buckets & $8(38 \%)$ \\
\hline Other (ie: swim socks or drag suits) & $4(19 \%)$ \\
\hline
\end{tabular}

*Participants could select all that apply

Approximately $91 \%$ of the participants were supervised during their resistance training. Supervision was most commonly provided by the swim coach (32\%), athletic trainer or strength coach (26\% each), a combination of both a swim coach and athletic trainer (11\%), and a combination of a swim coach and physical therapist (5\%). All 19 participants reported receiving correction of improper form during strength training. When determining the amount of weight used for strength training, 14 (67\%) reported the amount of resistance was determined on an individual basis, nine (43\%) reported the swimmer decides the amount of resistance, three (14\%) reported using their bodyweight, two (9.5\%) used a predetermined repetition maximum and one (4.8\%) reported all swimmers on the team use the same amount of weight. All but one participant reported using some type of resistance training in the pool. The types of in-pool resistance reported by participants can be viewed in Table 3. Nineteen of 21 (90.5\%) participants reported incorporating stretching into their training regimen. Strengthening/stretching programs reported by participants included routines that may not have been specifically targeted toward injury prevention since the interpretation of "injury prevention" was left up to the respondent.

\section{INJURY HISTORY}

Of the 21 survey participants, 11 (52.4\%) reported experiencing an injury during their swimming career that altered their weekly training, with five $(23.8 \%)$ reporting shoulder injuries as the cause of missed time. Six of the 21 swimmers (28.6\%) reported missing competitions due to injury, with an average of 1.5 competitions missed. Of the swimmers who reported an injury that altered their weekly training, 8 trained 15-21 hours/week, 2 trained 8-14 hours/week, and one trained $\leqslant 7$ hours/week. Freestyle $(n=12)$ was reported as the most common primary stroke (57\%). Eight (66.7\%) who identified freestyle as their primary stroke reported an injury that altered weekly training, whereas four (33.3\%) reported missing competition due to injury. Two swimmers (9.5\%) reported having had previous surgery related to a swimming injury. Of the six male survey participants, two (33.3\%) reported injuries that altered weekly training, while nine $(60 \%)$ of the 15 females reported injuries that altered weekly training.

Any mechanisms of injury reported were classified as acute (defined as any injury that was caused by a specific, identifiable event related to Para swimming activities), chronic (defined as any injury that developed over days, weeks, or months and was not associated with an acute event), or unknown chronicity (if the participant did not provide enough information in their survey response to classify the injury as acute or chronic). Table 4 provides an overview of injury characteristics described by participants, categorized by the eligible impairment types of Para swimmers. Of the five respondents with short stature, four (80\%) reported an injury that altered their weekly training and three (60\%) missed competition due to their injury. The shoulder was the most commonly reported body area across multiple impairment categories. 
Table 4. Injury Characteristics and Injury Prevention Program History - By Eligible Impairment

\begin{tabular}{|c|c|c|c|c|c|c|c|c|}
\hline & & \multicolumn{6}{|c|}{ Impairment Categories } & \multirow[b]{2}{*}{$\begin{array}{l}\text { Total } \\
\text { Participants } \\
(\mathrm{n}=21)\end{array}$} \\
\hline & & Hypertonia ( $n=2)$ & $\begin{array}{l}\text { Impaired } \\
\text { Muscle } \\
\text { Power* } \\
(n=3)\end{array}$ & $\begin{array}{l}\text { Impaired } \\
\text { Passive } \\
\text { Range of } \\
\text { Movement* } \\
(n=2)\end{array}$ & Limb Deficiency $(n=9)$ & $\begin{array}{l}\text { Short } \\
\text { Stature } \\
(n=5)\end{array}$ & Visual Impairment $(n=3)$ & \\
\hline \multicolumn{2}{|c|}{$\begin{array}{l}\text { Participants reporting injury } \\
\text { altering weekly training }\end{array}$} & $1(50 \%)$ & $\begin{array}{l}1 \\
(33.3 \%)\end{array}$ & $1(50 \%)$ & $2(22.2 \%)$ & $4(80 \%)$ & $3(100 \%)$ & $11(52.3 \%)$ \\
\hline \multicolumn{2}{|c|}{$\begin{array}{l}\text { Participants reporting missing } \\
\text { competition due to injury }\end{array}$} & --- & --- & --- & $1(11.1 \%)$ & $3(60 \%)$ & 2 (66.7\%) & $6(29 \%)$ \\
\hline \multirow{3}{*}{$\begin{array}{l}\text { Chronicity of } \\
\text { injuries } \\
\text { reported }\end{array}$} & $\begin{array}{l}\text { Acute } \\
\text { injuries }\end{array}$ & --- & --- & --- & --- & $3(60 \%)$ & $1(33.3 \%)$ & $4(19 \%)$ \\
\hline & $\begin{array}{l}\text { Chronic } \\
\text { injures }\end{array}$ & $1(50 \%)$ & $\begin{array}{l}1 \\
(33.3 \%)\end{array}$ & $1(50 \%)$ & $2(22.2 \%)$ & $1(20 \%)$ & --- & $5(23.8 \%)$ \\
\hline & $\begin{array}{l}\text { Injuries of } \\
\text { unknown } \\
\text { chronicity }\end{array}$ & --- & --- & --- & --- & --- & $2(66.7 \%)$ & $2(9.5 \%)$ \\
\hline \multirow{7}{*}{$\begin{array}{l}\text { Body part(s) } \\
\text { reported to be } \\
\text { injured (some } \\
\text { participants } \\
\text { reported } \\
\text { multiple) }\end{array}$} & Shoulder & $1(50 \%)$ & $\begin{array}{l}1 \\
(33.3 \%)\end{array}$ & $1(50 \%)$ & $2(22.2 \%)$ & --- & $1(33.3 \%)$ & $5(23.8 \%)$ \\
\hline & Knee & --- & --- & --- & --- & $1(20 \%)$ & --- & $1(4.8 \%)$ \\
\hline & Lower leg & --- & --- & --- & --- & $1(20 \%)$ & --- & $1(4.8 \%)$ \\
\hline & Ankle & --- & --- & --- & --- & --- & $1(33.3 \%)$ & $1(4.8 \%)$ \\
\hline & Abdomen & --- & --- & --- & --- & --- & $1(33.3 \%)$ & $1(4.8 \%)$ \\
\hline & $\begin{array}{l}\text { Multiple } \\
\text { fractures } \\
\text { (location } \\
\text { not } \\
\text { specified) }\end{array}$ & --- & --- & --- & --- & $2(40 \%)$ & --- & $2(9.5 \%)$ \\
\hline & $\begin{array}{l}\text { Multiple } \\
\text { tendon or } \\
\text { muscle } \\
\text { strains } \\
\text { (location } \\
\text { not } \\
\text { specified) }\end{array}$ & --- & --- & --- & --- & $1(20 \%)$ & --- & $1(4.8 \%)$ \\
\hline Reported & Participated & $1(50 \%)$ & --- & --- & 1 (11.1\%) & --- & $2(66.7 \%)$ & $4(19 \%)$ \\
\hline
\end{tabular}




\begin{tabular}{|c|c|c|c|c|c|c|c|c|}
\hline & & \multicolumn{6}{|c|}{ Impairment Categories } & \multirow[b]{2}{*}{$\begin{array}{l}\text { Total } \\
\text { Participants } \\
(\mathrm{n}=21)\end{array}$} \\
\hline & & Hypertonia ( $n=2)$ & $\begin{array}{l}\text { Impaired } \\
\text { Muscle } \\
\text { Power* } \\
(n=3)\end{array}$ & $\begin{array}{l}\text { Impaired } \\
\text { Passive } \\
\text { Range of } \\
\text { Movement* } \\
(n=2)\end{array}$ & Limb Deficiency $(n=9)$ & $\begin{array}{l}\text { Short } \\
\text { Stature } \\
(n=5)\end{array}$ & Visual Impairment $(n=3)$ & \\
\hline \multirow{4}{*}{$\begin{array}{l}\text { injury } \\
\text { prevention } \\
\text { program } \\
\text { participation }\end{array}$} & $\begin{array}{l}\text { in injury } \\
\text { prevention } \\
\text { and injured }\end{array}$ & & & & & & & \\
\hline & $\begin{array}{l}\text { Description } \\
\text { of injury } \\
\text { prevention } \\
\text { program }\end{array}$ & $\begin{array}{l}\text { Prehab program } \\
\text { prior to starting } \\
\text { practice } \times 10 \mathrm{~min}\end{array}$ & --- & --- & $\begin{array}{l}\text { Shoulder strengthening in } \\
\text { physical therapy } x 1 \text { hour weekly }\end{array}$ & --- & $\begin{array}{l}\text { 1) Injury prevention at } \\
\text { national team camps/ } \\
\text { international } \\
\text { competitions by team } \\
\text { support staff 2) Not } \\
\text { specified }\end{array}$ & --- \\
\hline & $\begin{array}{l}\text { Participated } \\
\text { in injury } \\
\text { prevention } \\
\text { and NOT } \\
\text { injured }\end{array}$ & $1(50 \%)$ & --- & --- & $2(22.2 \%)$ & --- & --- & $2(9.5 \%)$ \\
\hline & $\begin{array}{l}\text { Description } \\
\text { of injury } \\
\text { prevention } \\
\text { program }\end{array}$ & $\begin{array}{l}\text { Stretching, shoulder } \\
\text { and hip } \\
\text { strengthening } \\
\text { directed by strength } \\
\text { coach x45 min every } \\
\text { morning }\end{array}$ & --- & --- & $\begin{array}{l}\text { 1) Stretching, shoulder and hip } \\
\text { strengthening directed by } \\
\text { strength coach x } 45 \text { min every } \\
\text { morning 2) Exercises not specified } \\
\times 1.5 \text { hours weekly }\end{array}$ & --- & --- & --- \\
\hline
\end{tabular}


Table 5. Demographics of Interview Participants.

\begin{tabular}{|l|l|l|l|l|}
\hline Participant & $\begin{array}{l}\text { Age } \\
\text { (years) }\end{array}$ & Gender & Para Swimming Eligible Impairment(s) & $\begin{array}{l}\text { Para Swimming Sport Class (S/SB/ } \\
\text { SM) }\end{array}$ \\
\hline 1 & 26 & Male & Visual & $11 / 11 / 11$ \\
\hline 2 & 28 & Female & $\begin{array}{l}\text { Physical (limb deficiency and } \\
\text { hypertonia) }\end{array}$ & $8 / 7 / 8$ \\
\hline 3 & 30 & Female & Physical (hypertonia) & $3 / 3 / 3$ \\
\hline 4 & 23 & Female & Visual & $12 / 12 / 12$ \\
\hline 5 & 21 & Female & Physical (short stature) & $6 / 6 / 6$ \\
\hline 6 & 22 & Female & Physical (short stature) & $7 / 6 / 7$ \\
\hline
\end{tabular}

Eight of 21 participants (38.1\%) reported having current pain with an average intensity rating of 3.4 (SD 0.89), (on a 0 to 10 numerical rating scale, with 0 representing no pain and 10 representing the most severe pain). Participants experiencing pain reported the location of their current pain as follows: $23.8 \%$ reported pain in the shoulder, $9.5 \%$ in the arm, 9.5\% in the upper back and lower back, and $4.8 \%$ in the abdomen, elbow, hip, and knee.

\section{INJURY PREVENTION PROGRAMS AND TREATMENT}

Six (28.6\%) of the 21 participants reported participation in an injury prevention program, with four of the six $(66.7 \%)$ reporting injury. Seven $(46.7 \%)$ of the 15 participants who did not participate in an injury prevention program reported having a history of an injury. Injury prevention programs (as interpreted by the participant) ranged from a program at a national team camp to an individualized program that included stretching and strengthening 45 minutes each morning to prevent shoulder and hip injury.

Nine (42.9\%) of the 21 survey participants reported receiving physical therapy treatment due to injury, 9 (42.9\%) reported receiving chiropractic treatment, 10 (47.6\%) reported receiving a massage due to injury, and 4 (19\%) reported receiving no treatment at all. Treatments included kinesiotape ( $\mathrm{n}=9,42.9 \%)$, cupping ( $\mathrm{n}=7,33.3 \%)$, ASTYM $(\mathrm{n}=4,19 \%)$, electrical stimulation $(\mathrm{n}=8,38.1 \%)$, massage $(\mathrm{n}=16,76.2 \%)$, pneumatic compression $(\mathrm{n}=7,33.3 \%)$, and manual therapy $(n=8,38.1 \%)$. Three $(14.3 \%)$ participants responded to an open-ended question on the survey regarding any additional information on swimming and swimming injury as it pertains to their personal experiences and reported they had improvement of symptoms following the implementation of stretching and strengthening programs.

\section{PART II. INTERVIEW RESULTS}

Six Para swimmers who were U.S. Paralympics Swimming resident team members and at least 18 years old participated in the qualitative interviews, with demographics presented in Table 5.

Para swimmers interviewed represented both genders with diverse impairments and classification sport classes. The resultant themes from the interviews were categorized into four main topic categories: training, injury risk, in-

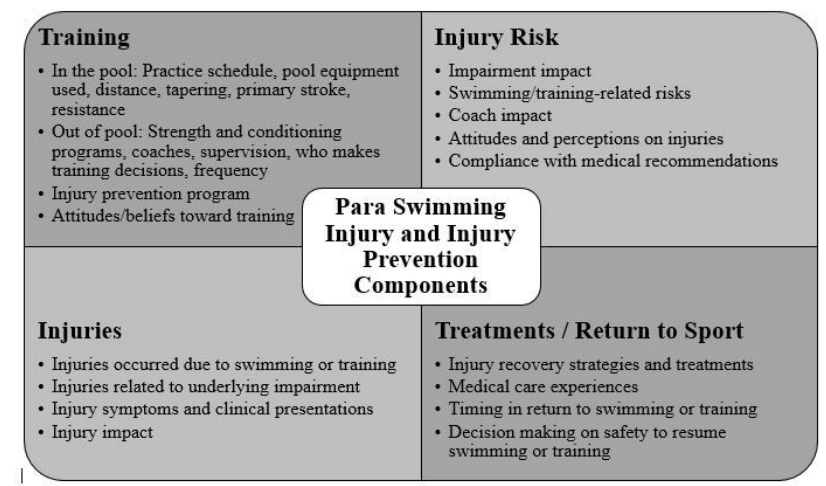

juries, and treatment and return to sport (Figure 2).

Training Theme*: Training is individualized and requires knowledgeable coaching and support personnel:* Interviewees noted the wide array of physical impairments makes the attitudes and beliefs towards training and injury vary between individuals in Para swimming. All 6 participants reported coaches, medical staff, and training personnel have an impact on their swimming career and that having access to a comprehensive, multidisciplinary team and resources was important for their training needs. As noted by Participant 06:
"Para athletes [need to] know that they're on that same elite level [as athletes without disabilities] and they need those same ... recovery tools or ..., prevention techniques. ... That's just something that I've realized since, ... making my first National team is I need those things just like an able-bodied athlete does, maybe just in a different way."

Para swimmers also recognized the value of having their training supervised by someone officially trained and experienced in working with athletes with disabilities who could recognize and understand the balance between allowing them to be resilient and push, but not overdo it to the point that risks injury. As per Participant 04:

"I'm very thankful to have coaches watching me and making sure I'm doing the proper technique. ... that was especially a big thing in therapy. I really had to 
have somebody help me because I used a lot of compensation methods that I never realized that I did until I was in therapy and I was supposed to be doing isolated exercises and I would compensate a ton. So they had to work really hard with me and help me to, to not compensate."

As is the case for all athletes, interviewees also noted it is important for Para swimmers to gradually return to their training regimens after a hiatus to avoid injuries. Some interviewees reported that time off from swimming may impact Para swimmers more than swimmers without disabilities, further emphasizing the importance of cross-training and participation in other activities.

Injury Risk Theme: Injury risk is unique in Para swimmers based on their underlying medical conditions, impairments, and adaptations to accommodate for their impairments: As per Participant 03:

"I think at the same time there was no real way for me to get the same range of motion or pull down my right arm in order to match my left arm, which would have

led to ... another form of ... compensation injury."

Some Para swimmers reported they learned to do their pre-habilitation or injury prevention programs based on their personal experience. Swimmers with visual impairment who require tappers also have to develop strong relationships with their tappers to anticipate the wall of the pool and prevent injury. However, most swimmers do not get a chance to practice with their tappers until the time surrounding a competition.

Injuries Theme: Para swimmers, compared to swimmers without disabilities, may experience a greater impact from their injuries on their daily lives: Interviewees reflected that Para swimmers, compared to swimmers without disabilities, may feel a more significant impact from injuries as some Para swimmers reported the water and swimming improved their function and everyday symptoms from their underlying disabilities. As per Participant 06:

\footnotetext{
“The water ... makes my body feel better and ... I don't feel as stiff and ... don't experience as many aches and pains as I do ... when I'm not in the water. So when there is an injury ... preventing me from being in the water, ... it definitely makes me upset. [...and] sad. [Be]cause it affects me a lot and I feel like ... it affects me a lot more than it would [affect] an able-bodied swimmer."
}

Interviewees also reported that their injuries can both be preventable and unpreventable due to unique risk factors from their underlying medical conditions. Injury symptoms and clinical presentation may be atypical due to some Para swimmers' underlying disabilities and their subsequent increased resilience and pain tolerance.

Treatment Theme: Interviewees reported both mixed experiences with medical treatment of their injuries and return to sport recommendations, with negative experiences causing significant barriers in their Para swimming career: One interviewee noted that replacing swimming with another activity is sometimes more helpful when recovering from injury or taking time off. Interviewees also expressed how swimming itself aids in the recovery process and how it assists with strengthening. Injuries as severe as fractures were noted by one interviewee with osteogenesis imperfecta and were not enough to hold her out of the pool for more than 3 days. Interviewees reported both positive and negative experiences and inconsistencies with medical care of their injuries - times when all of their specific medical needs were met due to great communication, but also when conflicting staff opinions limited training unnecessarily. Participant 01 and 03 summarized:

Participant 01: "the staff at [location omitted] ...was sometimes more of an obstacle than a help ... their head of a Sports Medicine didn't want me back in the pool after I had a pretty good attack. One day they called the ambulance, the whole 9 yards. ... And I [told] him [that] my neurologist cleared me, neurologist said [I'm] fine, [I'm] cleared to go... I can remember that really hurt my training pretty bad."

Participant 03: "Injuries that were not caught ... in time or misdiagnosed. So ... we've had to limit what we can and can't do as far as strokes. ... We were doing the wrong rehab program for quite some time, so we were only aggravating that initial injury to begin with..”

\section{DISCUSSION}

This study utilized a mixed-methods approach producing valuable data and perspectives on injuries, treatment, training practices, and participation in injury prevention in elite U.S. Para swimmers with physical and/or visual impairments. These results indicate that Para swimmers experience injuries at similar rates to swimmers without impairments. Additionally, the results of this study show there is a lack of injury prevention programs being utilized by Para swimmers and that individual Para swimmers have unique needs due to their disabilities and impairments.

The most common site of injury in the athletes in the current study was the shoulder, which is consistent with other studies that focused on Para swimmers, ${ }^{22}$ Para athletes across a variety of sports, $, 8,10,12$ and swimmers without disabilities. ${ }^{16,23}$ The percentage of U.S. Para swimmers reporting injuries in our survey was higher than what has been reported in other studies. ${ }^{10,12}$ However, it is difficult to compare the present study to others because of differences in methodology, including data sources and how "injury" was defined. Derman and colleagues evaluated prospective cohort data from a total of 3657 athletes from 78 countries at the Rio 2016 Summer Paralympic Games. ${ }^{10}$ The authors reported that within the sport of Para swimming 42 of the 492 Para swimmers (8.5\% ) sustained injuries during the Rio 2016 Paralympic Games. ${ }^{10}$ Whether injuries were acute, acute on chronic, or chronic was not reported specifically for Para swimming. Willick and colleagues examined 62 injuries in Para swimmers $(12.4 \%$ of all Para swimmers) during the London 2012 Paralympic Games. Of these injuries, $47 \%$ were reported to be "acute" and $16 \%$ were reported to be "acute on chronic." 12

The current study's retrospective data was not specific to one event or time point, but rather across the participants' careers as competitive Para swimmers. While studies conducted by Derman ${ }^{10}$ and Willick ${ }^{12}$ reported prospective data from a much larger sample size during the duration of 
a single Paralympic Games, this present study is the first to report data exclusively from U.S. Para swimmers, specifically gathering data about injuries that impacted weekly training throughout the swimmer's career. This present study focused on injuries that altered weekly training or competition participation, while studies conducted by Derman $^{10}$ and Willick ${ }^{12}$ included injuries that may not have altered weekly training or competition participation.

The participants in the present study reported more chronic than acute injuries compared to the those included in Paralympic Games injury surveillance studies, which could be explained by gathering injury history data that may not have needed medical attention. Thus, the present survey may have been more sensitive in capturing chronic injuries compared to Derman ${ }^{10}$ and Willick ${ }^{12}$ studies. This is especially true if Para athletes are more likely to seek medical attention for acute injuries and not for chronic injuries at the Games, which may occur for multiple reasons. As reported by participants in this study, Para swimmers may have a complicated medical history and some have reported negative experiences when seeking medical care for symptoms leading to unnecessary training/competition restrictions. The qualitative interview discussion about injuries noted a common theme reflecting Para swimmers' beliefs that time in the water improved their function in everyday life. Therefore, time away from the pool due to injury may be of greater detriment for Para swimmers than swimmers without disabilities. Fear of repeat negative experiences may discourage Para swimmers from seeking medical care until absolute necessary, such as in acute injuries causing significant pain or functional limitations, or only when chronic injuries have been exacerbated and come to a point where they are no longer tolerable. Further evidence is needed to understand the impact of an injury on various psychosocial, functional, and sports participation outcomes in Para swimmers compared to swimmers without disabilities.

Current guidelines proposed for injury prevention in swimmers without disabilities suggest that strength training be supervised by a certified strength and conditioning specialist, athletic trainer, or physical therapist to prevent injury. ${ }^{24}$ There are no published guidelines for those with impairments/disabilities. Most survey participants in our study (90.5\%) reported supervision of their out of pool resistance training, with $61.9 \%$ being at least occasionally supervised by an athletic trainer, strength coach, or physical therapist, therefore meeting guidelines for best practice of strength training, at least according to literature for athletes without disabilities. ${ }^{24}$ The majority of survey participants (90.5\%) also completed stretching as part of their regular training routine, which is in alignment with current recommendations for swimmers without disabilities. ${ }^{16}$ However, since both of these strengthening and stretching guidelines were created for swimmers without disabilities in mind, further research is needed to evaluate effective techniques for strengthening and stretching specifically in Para swimmers, with consideration of the broad spectrum of medical diagnoses, impairments, and functional abilities Para swimmers represent.

Although many of the survey participants reported performing resistance and stretching programs, while 15
(71.4\%) reported they did not participate in a specific injury prevention program, half of this group reported an injury. Out of the remaining survey participants who did participate in an injury prevention program, $66.7 \%$ of these participants still reported an injury. In swimmers without disabilities, there are proposed algorithms for injury prevention, including careful monitoring of training volume, intensity, and duration by coaches and physicians while also looking out for stroke alterations that could represent compensation for pain or injury. ${ }^{16}$ It is also recommended that swimmers without disabilities in general work on endurance training (strengthening, stabilization, and flexibility) of core muscles to avoid excessive anterior pelvic tilt and lumbar lordosis, and also focus on scapular strengthening before primary rotator cuff muscles strengthening as part of their injury prevention program. ${ }^{16}$ However, due to the uniqueness of each Para swimmer, the results of the present study highlight that an injury prevention plan should include individual analyses of the Para swimmers' biomechanics and a strong understanding of how their underlying medical condition impacts their movements in the water, fatigue, and risk of injury. Those that participated in the qualitative portion of this study also emphasized the value of having support from a multidisciplinary team well-experienced in working with Para athletes. In collaboration with the Para athlete, coach(es), and other healthcare specialists (e.g. sports psychologist, nutritionist, etc.), such individualized injury prevention programs could be prescribed by physiatrists, sports medicine physicians, physical therapists, and/or athletic trainers experienced in evaluating the needs of the Para athlete.

\section{LIMITATIONS}

The small sample size of this study limits the ability to generalize the results, and prevents detailed analysis by individual impairment types and sport classes for classification. Further limitations included the potential for response bias and having to rely on the participant's understanding and interpretation of their injury diagnosis. Injury prevalence or incidence was not able to be calculated from the data as the survey did not define a time period for participants to report injuries. A specific definition for "injury" and "injury prevention program" also was not provided to survey participants, possibly leading to different interpretations of what entails an injury or injury prevention program, and over-or under-reporting of each. Moreover, the survey inquired about injuries that altered weekly training versus injury that caused the participant to miss a competition, but did not gather data about injuries that did not result in these consequences, thus potentially underrepresenting the injury history of Para swimmers in our study.

\section{CONCLUSION}

Injuries that alter weekly training are common in U.S. Para swimmers, although only a small number participate in injury prevention programs. Qualitative results revealed that many Para swimmers believe they experience injuries based on their specific impairments and compensations. Injury prevention programs should be specifically designed for in- 
dividual Para swimmers due to the difference in training needs based on underlying medical conditions, impairments, and function. Future research should examine coaching knowledge and whether access to individualized, multidisciplinary programs can reduce injury prevalence among this at-risk population.

\section{CONFLICTS OF INTEREST}

None.

Submitted: March 08, 2021 CST, Accepted: September 19, 2021 CST 


\section{REFERENCES}

1. International Paralympic Committee. History of the Paralympic movement. Accessed June 27, 2020. ht tps://www.paralympic.org/ipc/history

2. Wilson PE, Clayton GH. Sports and disability. Phys Med Rehabil. 2010;2(3):S46-S54. doi:10.1016/i.pmri.2 $\underline{010.02 .002}$

3. International Paralympic Committee. What is classification? Accessed June 27, 2020. https://www.p aralympic.org/classification

4. International Paralympic Committee. World Para Swimming classification rules and regulations. Updated. Published online August 20, 2020. https://w ww.paralympic.org/swimming/classification

5. Fagher K, Lexell J. Sports-related injuries in athletes with disabilities. Scand J Med Sci Sports. 2014;24(5):e320-e331. doi:10.1111/sms.12175

6. Fagher K, Forsberg A, Jacobsson J, Timpka T, Dahlström Ö, Lexell J. Paralympic athletes' perceptions of their experiences of sports-related injuries, risk factors and preventive possibilities. Eur J Sport Sci. 2016;16(8):1240-1249. doi:10.1080/1746139 1.2016.1192689

7. Webborn N, Emery C. Descriptive epidemiology of Paralympic sports injuries. Phys Med Rehabil. 2014;6:S18-S22. doi:10.1016/j.pmrj.2014.06.003

8. Rudolph L, Willick S, Teramoto M, Cushman DM. Adaptive sports injury epidemiology. Sports Med Arthrosc Rev. 2019;27(2):e8-e11. doi:10.1097/jsa.0000 $\underline{000000000243}$

9. Derman W, Schwellnus M, Jordaan E, et al. Illness and injury in athletes during the competition period at the London 2012 Paralympic games: Development and implementation of a web-based surveillance system (WEB-IISS) for team medical staff. Br J Sports Med. 2013;47(7):420-425. doi:10.1136/bjsports-201 $\underline{3-092375}$

10. Derman W, Runciman P, Schwellnus M, et al. High precompetition injury rate dominates the injury profile at the Rio 2016 Summer Paralympic Games: A prospective cohort study of 51198 athlete days. $\mathrm{Br} \mathrm{J}$ Sports Med. 2018;52(1):24-31. doi:10.1136/bjsports-2 017-098039

11. Derman W, Runciman P, Jordaan E, et al. High incidence of injuries at the Pyeongchang 2018 Paralympic winter games: A prospective cohort study of 6804 athlete days. Br J Sports Med. 2020;54(1):38-43. doi:10.1136/bjsports-2018-100170
12. Willick SE, Webborn N, Emery C, et al. The epidemiology of injuries at the London 2012 Paralympic games. Br J Sports Med. 2013;47(7):426-432. doi:10.1136/bjsports-2013-09237 $\underline{4}$

13. Reynolds J, Stirk A, Thomas A, Geary F. Paralympics--Barcelona 1992. Br J Sports Med. 1994;28(1):14-17. doi:10.1136/bjsm.28.1.14

14. Tate A, Harrington S, Buness M, Murray S, Trout $\mathrm{C}$, Meisel C. Investigation of in-water and dry-land training programs for competitive swimmers in the United States. J Sport Rehabil. 2015;24(4):353-362. do i:10.1123/jsr.2014-0205

15. Shoulder injury in competitive swimming: Strategies for early identification and prevention. Accessed August 20, 2020. https://www.usaswimmin g.org/docs/default-source/clinics/online-clinic-series/ sports-med/4-15-15-evaluation-and-management-o f-should-pain-in-swimmers---dr-scott-rodeo.pdf?sfvr $\underline{s n=4}$

16. Wanivenhaus F, Fox AJS, Chaudhury S, Rodeo SA. Epidemiology of injuries and prevention strategies in competitive swimmers. Sports Health. 2012;4(3):246-251. doi:10.1177/1941738112442132

17. Fearing M, Harrington SE. Understanding injury and injury prevention in Paralympic sport. Sports Med Health Sci. 2017;49(5S):1093. doi:10.1249/01.mss.000 0520012.78593.1f

18. Sax LJ. Our incoming students: What are they like? About Campus. 2003;8(3):15-20. doi:10.1177/108 $\underline{648220300800305}$

19. Kaplowitz MD, Hadlock TD, Levine R. A comparison of web and mail survey response rates. Public Opin Q. 2004;68(1):94-101. doi:10.1093/poq/nf $\underline{\text { h006 }}$

20. Braun V, Clarke V. Using thematic analysis in psychology. Qual Res Psychol . 2006;3(2):77-101. doi:1 $\underline{0.1191 / 1478088706 q p 0630 a}$

21. Henderson R, Rheault W. Appraising and incorporating qualitative research in evidence-based practice. J Phys Ther Educ. 2004;18(3):35-40. doi:10.1 097/00001416-200410000-00005

22. Silva MM e, Bilzon J, Duarte E, Gorla J, Vital R. Sport injuries in elite Paralympic swimmers with visual impairment. J Athl Train. 2013;48(4):493-498. $\underline{\mathrm{d}}$ oi:10.4085/1062-6050-48.4.07 
23. Chase KI, Caine DJ, Goodwin BJ, Whitehead JR, Romanick MA. A prospective study of injury affecting competitive collegiate swimmers. Res Sports Med. 2013;21(2):111-123. doi:10.1080/15438627.2012.7572 24
24. Haff GG, Triplett NT. Essentials of strength training and conditioning 4ed. Human Kinetics. Published online 2015. 


\section{SUPPLEMENTARY MATERIALS}

\section{Appendix 1}

Download: https://ijspt.scholasticahq.com/article/31173-injury-and-injury-prevention-in-united-states-paraswimming-a-mixed-methods-approach/attachment/78474.pdf?auth token=OFREm9TI21pye-Z-mgtp

\section{Appendix 2}

Download: https://ijspt.scholasticahq.com/article/31173-injury-and-injury-prevention-in-united-states-paraswimming-a-mixed-methods-approach/attachment/78723.pdf?auth token=OFREm9TI21pye-Z-mgtp 